\title{
A Novel Variant of Human Grb7 Is Associated with Invasive Esophageal Carcinoma
}

Shinji Tanaka, ${ }^{*}$ Masaki Mori, ${ }^{*}$ Tsuyoshi Akiyoshi, ${ }^{*}$ Yoichi Tanaka,§ Ken-ichi Mafune,\| Jack R. Wands,, and Keizo Sugimachi *Department of Surgery, Medical Institute of Bioregulation, Kyushu University, Beppu, Japan; ${ }^{\ddagger}$ Department of Surgery II, Faculty of Medicine, Kyushu University, Fukuoka, Japan; ${ }^{\S}$ Department of Surgery, Saitama Cancer Center, Saitama, Japan; Department of Surgery, Faculty of Medicine, University of Tokyo, Tokyo, Japan; and ${ }^{\mathbb{\pi}}$ Cancer Center, Massachusetts General Hospital, Harvard Medical School, Boston, Massachusetts

\begin{abstract}
The cDNAs of a putative growth factor-bound (Grb) 7 signal transduction molecule and Grb7V novel splice variant were isolated from an invasive human esophageal carcinoma. Although both Grb7 isoforms share homology with the Mig-10 cell migration gene, the Grb7V isoform lacks 88 base pairs in the $\mathrm{C}$ terminus; the resultant frame shift leads to substitution of an $\mathrm{SH} 2$ domain with a short hydrophobic sequence. The wild-type Grb7 protein, but not the Grb7V isoform, is rapidly tyrosyl phosphorylated in response to EGF stimulation in esophageal carcinoma cells. Analysis of human esophageal tumor tissues and regional lymph nodes with metastases revealed that Grb7V was expressed in $40 \%$ of Grb7-positive esophageal carcinomas. More importantly, Grb7V expression was enhanced after metastatic spread to lymph nodes as compared to the original tumor tissues. Finally, transfection of an antisense Grb7 RNA expression construct lowered endogenous Grb7 protein levels and suppressed the invasive phenotype exhibited by esophageal carcinoma cells. These findings suggest that Grb7 isoforms are involved in cell invasion and metastatic progression of human esophageal carcinomas. (J. Clin. Invest. 1998. 102:821827.) Key words: Grb7 • Mig-10 • splice variant • esophageal carcinoma $\bullet$ metastasis
\end{abstract}

\section{Introduction}

Metastatic spread of tumor cells is one of the major risk factors affecting clinical prognosis. There are several sequential steps in this process including cell migration into the surrounding host tissue, infiltration, and penetration into blood and/or lymphatics for dissemination, attachment to capillary beds of distant organs, cell extravasation, and subsequent growth in tissues (1). Some of the mechanisms involving normal cell migration observed during development are believed to be closely associated with the properties of tumor cell invasion. Thus, the so-called "cell migration genes" may be frequently used by cancer cells to allow for metastatic spread of disease.

Address correspondence to Shinji Tanaka, Department of Surgery, Medical Institute of Bioregulation, Kyushu University, 4546 Tsurumibaru, Beppu 874-0838, Japan. Phone: 81-977-27-1650; FAX: 81977-27-1607; E-mail: shinji@tsurumi.beppu.kyushu-u.ac.jp

Received for publication 27 January 1998 and accepted in revised form 17 June 1998.

J. Clin. Invest.

(C) The American Society for Clinical Investigation, Inc. 0021-9738/98/08/0821/07 \$2.00

Volume 102, Number 4, August 1998, 821-827

http://www.jci.org
One of the most interesting approaches to define molecular components involved in the control of cell movement is the genetic analysis of mutations that disrupt specific cell migration patterns and the subsequent characterization of the corresponding genes involved in these processes. Caenorhabditis elegans is an excellent animal model to perform a genetic analysis of cell migration (3). Positional cloning of the corresponding genes have defined various key molecules required for cell migration during embryogenesis. For example, several mutations affecting the long-range anterior migration of the canal-associated neurons during embryogenesis have been defined (4). Characterization of the Mig-10 gene has revealed important information regarding such cell migration associated events (5). The Mig-10 gene encodes for two isoforms that contain proline-rich sequences in both of the $\mathrm{NH}_{2}$ and $\mathrm{COOH}$ termini and a distinct central region composed of $\sim 300$ amino acids with a pleckstrin homology $(\mathrm{PH})^{1}$ domain. Interestingly, the central region of Mig-10 has been found to be shared by a recently described family of mammalian Src-homology-2 (SH2) domain-containing proteins designated as growth factorbound (Grb) 7, Grb10/IRb, and Grb14 (6, 7, 8). These molecules appear to function as essential components in signal transduction pathways after receptor tyrosine kinase (RTK) activation by EGF, insulin, or PDGF. The structural homology between the Grb7 family and Mig-10 proteins in the central part of the molecule has been designated as the GM region (5). The Grb7 family of proteins also contains a proline-rich sequence in the $\mathrm{NH}_{2}$ terminus and an $\mathrm{SH} 2$ domain in the $\mathrm{COOH}$ terminus, whereas the Mig-10 protein lacks such a domain.

Because of these structural similarities that may imply a biologic function with respect to cell migration, we searched for the expression of Grb7 and potential isoforms in esophageal carcinomas with metastatic spread to adjacent tissues (9). In this study, a novel splice variant designated as Grb7V was isolated and characterized. We found that both Grb7 and Grb7V contain the GM domain. However, the Grb7V isoform lacks an $\mathrm{SH} 2$ domain in the $\mathrm{COOH}$ terminus. Analysis of the human esophageal tumor tissues revealed that enhanced expression of Grb7 and Grb7V was associated with metastatic progression of the disease. Our findings suggest a role for these proteins in cell migration and invasion by human esophageal carcinomas.

\section{Methods}

Cloning of human Grb7 cDNA. The $\mathrm{NH}_{2}$-terminal sequence and GM region of the human Grb7 cDNA has been previously reported (9). To clone the full-length cDNA of human Grb7, we used RACE and degenerate PCR primer sequences reported for murine Grb7 as de-

1. Abbreviations used in this paper: Grb, growth factor-bound; $\mathrm{PH}$, pleckstrin homology; PTP, protein tyrosine phosphatase; RT, reverse transcriptase; RTK, receptor tyrosine kinase; SH, Src-homology. 
scribed (6). Total RNA was extracted from an esophageal carcinoma tissue or from the KYSE410 esophageal carcinoma cell line followed by reverse transcriptase (RT) PCR amplification (9). The PCR products were cloned using the TA cloning kit (Invitrogen Inc., Carlsbad, CA) and DNA sequences determined by a cycle sequencing procedure (Applied Biosystems Inc., Foster City, CA). To certify the presence of transcripts in esophageal carcinoma cells, the full coding region of human Grb7 was amplified by RT-PCR using the two primers (5'-GGACAAGGGCACACAACTGGTTC-3' and 5'-CGCCCCAGATCCACTGGATGG-3').

Analysis of Grb7 protein expression in human esophageal carcinoma cells. Grb7 protein expression was detected by immunoblot analysis using three different antibodies directed against the $\mathrm{NH}_{2}$-terminal 1-205 aa residues of the Grb7 proline-rich and GM regions (Transduction Laboratories, Lexington, $\mathrm{KY}$ ), $\mathrm{NH}_{2}$-terminal 2-21 aa residues (N-20; Santa Cruz Biochemistry, Santa Cruz, CA) and COOH-terminal 516-535 aa residues (C-20; Santa Cruz Biochemistry) as described (10). Cell lysates were prepared in cold Triton-lysis buffer (50 mM Tris- $\mathrm{HCl}$, pH 7.5 containing 1\% Triton, 2 mM EGTA, $10 \mathrm{mM}$ EDTA, $100 \mathrm{mM} \mathrm{NaF}, 1 \mathrm{mM} \mathrm{Na} 4 \mathrm{P} 2 \mathrm{O} 7,2 \mathrm{mM} \mathrm{NaVO} 4,1 \mathrm{mM}$ phenylmethylsulfonyl fluoride, $25 \mathrm{mg} / \mathrm{ml}$ aprotinin, $3.5 \mathrm{mg} / \mathrm{ml}$ pepstatin A and $25 \mathrm{mg} / \mathrm{ml}$ leupeptin) after cells were treated with 6-h serum starvation followed by the addition of $100 \mathrm{ng} / \mathrm{ml}$ EGF for $10 \mathrm{~min}$. Next, $100 \mu \mathrm{g}$ of total protein was electrophoresed through SDS-polyacrylamide gels and proteins transferred onto Immobilon-P membranes (Millipore Corp., Bedford, MA). Immunodetection of proteins was performed with Grb7 antibodies using the enhanced chemiluminescence system (Amersham Corp., Arlington, IL). To determine tyrosyl phosphorylation of Grb7, cell lysates containing $500 \mu \mathrm{g}$ of protein were incubated with $10 \mu \mathrm{g}$ of the Grb7 antibody and immunoprecipitated with protein A-agarose. The immunoprecipitates were then subjected to SDS-polyacrylamide gel electrophoresis followed by immunodetection with the specific antibody (PY20) directed against phosphotyrosine residues (Transduction Laboratories).

Analysis of Grb7 expression in human esophageal carcinoma tissue and tumor metastatic to regional lymph nodes. To analyze the pattern of Grb7 expression in clinical samples, we studied 43 primary squamous cell esophageal tumors and eight metastatic lymph nodes obtained at the time of surgical resection. Amplification of transcripts by 25 cycle RT-PCR was performed using the following primers as previously described (9); Grb7: 5'-GCCTGGAGGAAGAAGACAAACCAC-3' and 5'-CTCCTCATCCCGTCCCCTGTGG-3' (product size $=505 \mathrm{bp}$ or $417 \mathrm{bp}$ ). As a control, we performed RT-PCR analysis of glyceraldehyde-3-phosphatase dehydrogenase mRNA (GAPDH) using 5'-GTCAACGGATTTGGTCTGTATT-3' and 5'-AGTCTTCTGGGTGGCAGTGAT-3' sequences as primers (product size $=560 \mathrm{bp}$ ). All PCR primers were selected to span introns in order to detect specific mRNA sequences. To detect Grb7 protein expression, tissue lysates were prepared in cold Triton-lysis buffer and $100 \mu \mathrm{g}$ of total protein was electrophoresed through SDS-polyacrylamide gels and proteins transferred onto Immobilon-P membranes (Millipore Corp.). Immunodetection of proteins was performed with Grb7 antibodies using the enhanced chemiluminescence system (Amersham Corp.). For histological examination, tissues were fixed with periodate-lysine-paraformaldehyde at $4^{\circ} \mathrm{C}$ at the time of surgical resection, embedded in OCT compound (Miles, Elkhart, IN), and stored at $-80^{\circ} \mathrm{C}$. In addition, specimens $(n=20)$ were stained with hematoxylin-eosin and cellular identification of the Grb7 protein was performed with an antibody specific for the $\mathrm{NH}_{2}$ terminus followed by immunodetection using the avidin-biotin-peroxidase complex method.

Effects of antisense Grb7 mRNA on invasion of human esophageal carcinoma cells. The 5'-region of Grb7 was amplified by PCR and subcloned in the reverse orientation into the pcDNA3 vector and subsequently transfected into KYSE410 esophageal carcinoma cells followed by G418 selection as described (11). After selection in the presence of $600 \mu \mathrm{g} / \mathrm{ml}$ of G418, the levels of Grb7 protein were examined in each clone by immunoblot analysis using an anti-Grb7 anti- body directed against the $\mathrm{NH}_{2}$ terminus. Grb2 protein expression was also analyzed as a control using an anti-Grb2 rabbit polyclonal antibody (Santa Cruz Biotechnology). Cell growth in culture was assessed as described (11). Assays of cell invasion properties were performed according to Albini et al. (14). This technique uses a modified Boyden chamber with polyethylene terephthalate filter inserts coated with a Matrigel matrix in 24-well plates containing 8-mm pores. In brief, $10^{5}$ esophageal tumor cells were suspended in serum-free medium with $0.5 \% \mathrm{BSA}$, and plated onto the upper chamber followed by filling the lower chamber with the same medium in the presence or absence of $100 \mathrm{ng} / \mathrm{ml}$ EGF. Cells were then cultured for $18 \mathrm{~h}$, fixed with $5 \%$ glutaraldehyde in PBS, and stained with $0.5 \%$ trypan blue in $2 \% \mathrm{Na}_{2} \mathrm{CO}_{3}$. Cells on the upper side of the filter were carefully removed and those cells invading the lower side were counted by microscopic examination. The mean migration rate of three independent experiments was determined for each clone with reduced Grb7 protein expression as the result of antisense effects.

\section{Results}

Two isoforms of human Grb7 are found in esophageal carcinomas. Previous studies have established that coexpression of Grb7 and RTK were associated with invasive esophageal carcinomas. However, 30\% of Grb7-positive esophageal tumors did not express RTK (9). To analyze the pattern of Grb7 expression in these invasive carcinomas, a full-length human Grb7 cDNA was isolated from a cDNA library prepared from an esophageal carcinoma using a partial $\mathrm{NH}_{2}$-terminal sequence of Grb7 (9). Two individual cDNA clones (2.2 and 2.1 $\mathrm{kb}$ ) were obtained and designated as human Grb7 and Grb7V spliced variant. These two isoforms were also detected in the human esophageal carcinoma cell line KYSE410. The human Grb7 cDNA encodes for 532 aa (Fig. 1) and this molecule shares $90 \%$ identity with the murine Grb7 protein as reported by Margolis et al. (6). The predicted Grb7 protein contains a proline-rich sequence in the $\mathrm{NH}_{2}$ terminus and a $\mathrm{SH} 2$ domain in the $\mathrm{COOH}$ terminus. The $\mathrm{Grb} 7$ central region includes a $\mathrm{PH}$ domain and is homologous to the Mig-10 cell migration molecule identified in $C$. elegans as shown in Fig. 2, $A$ and $B$.

In contrast, the Grb7V isoform lacks an 88-bp region encoding for the $\mathrm{SH} 2$ domain found in human Grb7. In the Grb7V cDNA, a frame shift has led to a coding region for 447 amino acids and the deleted $\mathrm{SH} 2$ domain has been substituted with a short hydrophobic sequence in the $\mathrm{COOH}$ terminus (Fig. $2 \mathrm{~B}$ ). It is of interest that this sequence shares $50 \%$ identity with the $\mathrm{COOH}$-terminal tail of the human homeobox protein HoxB4 (SGGAAGSAGGPPGRPPNGGPRAL; underlined are the identical sequences between the two proteins) (12).

Expression and tyrosyl phosphorylation of Grb7 isoforms in esophageal carcinoma cells. We searched for in vitro expression of Grb7 isoforms in the KYSE410 human esophageal carcinoma cell line by RT-PCR. As shown in Fig. $3 A$, two cDNA fragments of 1731 and 1643 bp in length were recognized and certified as human Grb7 and Grb7V by direct sequencing. Immunoblot analysis using an antibody directed against the $\mathrm{NH}_{2}$-terminal region of Grb7 (Transduction Laboratories) revealed two distinct proteins of 59 and $50 \mathrm{kD}$ that are the predicted sizes of the Grb7 and Grb7V proteins, respectively (Fig. 3 B, Grb7-N). In contrast, a different Grb7 antibody directed against the $\mathrm{COOH}$ terminus (C-20; Santa Cruz Biochemistry) identified the 59-kD protein of Grb7 but not the $50-\mathrm{kD}$ protein of $\mathrm{Grb} 7 \mathrm{~V}$, as it is truncated at the $\mathrm{COOH}$ 
Grb7

\begin{tabular}{|c|c|}
\hline 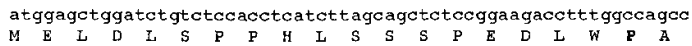 & $\begin{array}{l}60 \\
20\end{array}$ \\
\hline ot gggacecctectgggactccecqgececetgatacccetctgectgaggaggtaalag & 120 \\
\hline 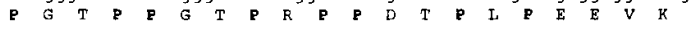 & 40 \\
\hline aggtcecagcetctcctcatcccaaccacc ggcaggaaacttcgagaggaggagaggegt & 180 \\
\hline 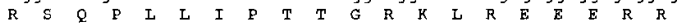 & 60 \\
\hline gecacctocctcocctotatccccaaccocttccct gagetctgcagtcetccotcacag & 240 \\
\hline 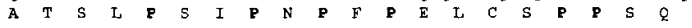 & 80 \\
\hline agcccaattctcggggggccectccagtgcaagggggget getcccecglgat gccagecgc & 300 \\
\hline 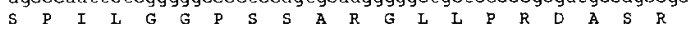 & 100 \\
\hline ccccatgtagtaa aggtgt acagtgaggat ggggcetgcaggtetgtggaggtggcagca & 360 \\
\hline$P$ H V V V & 120 \\
\hline ggt gecacagctcgec acgtgtgtgaaat got ggt gca gegagetcacgecttga ge gac & 420 \\
\hline 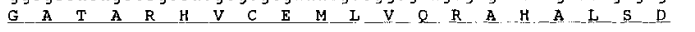 & 140 \\
\hline gagacctgggggetggtggagt gccacceccacetagcactggageggggtttggaggac & 480 \\
\hline 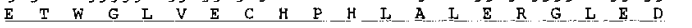 & 160 \\
\hline cacgagtccgtggtggaagtgeaggetgcetggecegt gggeggagata gecgettegte & 540 \\
\hline 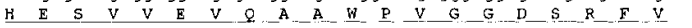 & 180 \\
\hline ttccggaaaacttcgccaagt acgaactgttcaagagctcccaacactccctgttccca & 00 \\
\hline 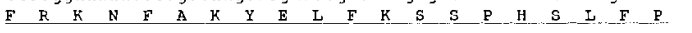 & 200 \\
\hline gaaaaatggtctccagctgtctcgatgcacacactggtatatcccatgaa & 60 \\
\hline 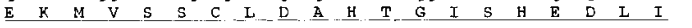 & 220 \\
\hline cagaacttcctgaatgctggcagctttcetgagatccagggetttetg & 20 \\
\hline 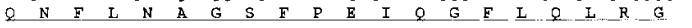 & 240 \\
\hline ttggaa ac gctt & 780 \\
\hline $\begin{array}{llllllllllllllllll}G & R & K & L & W & K & R & F & F & C & F & L & R & R & S & G & L & Y\end{array}$ & 260 \\
\hline tccaccaagqgcacetctaaggatccgaggcacctgcagtacgtggcagat & 10 \\
\hline S T K G T S K D P R R H L Q Y V V A D & 280 \\
\hline ctctacgggatgcceactgacttoc & 00 \\
\hline S N V V Y V V V & 300 \\
\hline tetgtgteaagcccaacaagcttcgaaatgga & 960 \\
\hline 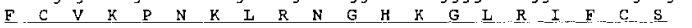 & 320 \\
\hline gaagat gagcagagoc gcacetgct ggctggctgcettcogectettcaagtacg & 1020 \\
\hline 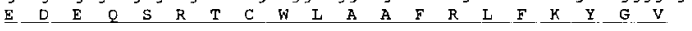 & 340 \\
\hline agctgtacaaga att accagcaggeacagtctcgecatctgcatccatett & 1080 \\
\hline 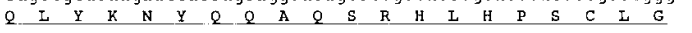 & 360 \\
\hline 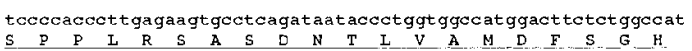 & $\begin{array}{l}1140 \\
380\end{array}$ \\
\hline & \\
\hline gct gggegt gtcattgagaacccecgggaggetct gagt gtggacotggaggaggcecag & 1200 \\
\hline $\begin{array}{lllllllllllllllllllll}\text { A } & G & R & V & I & E & \text { N } & \text { P } & R & \text { E } & \text { A } & \text { L } & \text { S } & \text { V } & \text { A } & \text { L } & \text { E } & \text { E } & \text { A } & Q\end{array}$ & 400 \\
\hline gcctggaggaagaagacaaaccaccgectcagcctgceca & 1260 \\
\hline 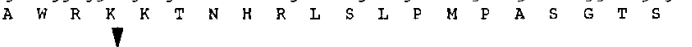 & 420 \\
\hline ctcagtgcagccatccaccgcacccaactctggttceacgggcgeatttccegtgaggag & 1320 \\
\hline 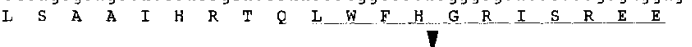 & 440 \\
\hline eggectgttectggtecggga & 1380 \\
\hline 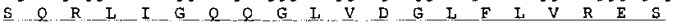 & 460 \\
\hline cageggaacceccagggctttgt & 1440 \\
\hline 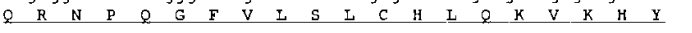 & 480 \\
\hline ctcatcctgecgagegaggaggagggtcgect & \\
\hline 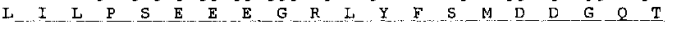 & 500 \\
\hline cgettcactgacete & \\
\hline 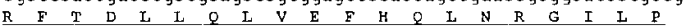 & 520 \\
\hline & \\
\hline $1 \mathrm{t}$ & 532 \\
\hline
\end{tabular}

Grb7V

atggagetggatctgtctceacctcatct agcagctetccggaagacett ggecagec 60

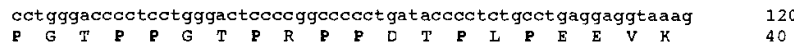

aggtcccagcctctcetcatcccaacc accggcaggaaacttcgagaggaggagaggcgt 180

gecacctcecteccetctateccaacecettcectgagetetgeagtectcectcacag 240

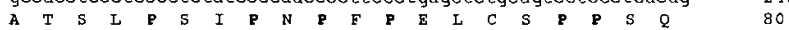

agcccaattetcgggggecectceagtgeaaggggget getccecegegatgecagecge 300

$\begin{array}{lllllllllllllllllllll}S & P & I & L & G & G & P & S & S & A & R & G & L & L & P & R & D & A & S & R & \end{array}$

ccccatgtagtaaaggt gtacagtgaggatggggcctgcaggtctgtggaggtggcagca

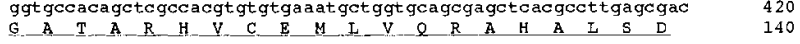
gagacct gggggct tggt ggagt gceacccceacctagcactggagc gqggtttggaggac 480

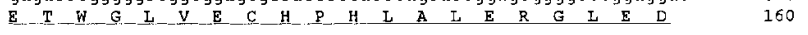
cacgagtccgtggtggaagtgcaggct gectggcecgt gggeggagatagce gcttcgtc $\quad 540$

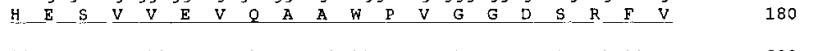
ttccggaaaact tcgceaagtacgaactgttcaagagctccecacactccetgttceca 600

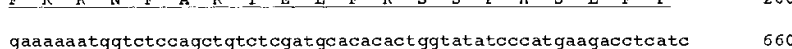

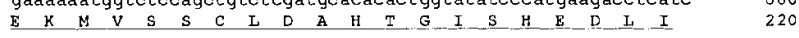
cagaacttcetgaatgctggcagctttcetgagatceagggetttetgeagctgcggggt $\quad 720$

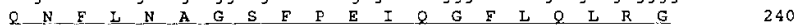
tcaggacggaagctttggaaacgetttttctgtttcttgcgcegatctggcetctattac $\quad 780$

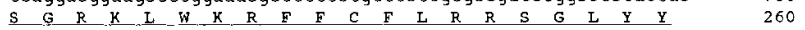
tccaccaagggcacctctaaggatcogaggcacctgeagtacgtggeagatgtgaacgag 840 S T K G T S K D P R H L Q Y V A D.V N E 280 tccaacgtgtacgtggt gacgeagggecgeaagctctacgggatgcceactgactteggt 900 S N V Y.V V V T Q G R K I Y G G M P T D F G 300 ttctgtgtcaagcccaacaagcttcgaaatggacacaaggggettcggatcttctgcagt 960 F C V K P N K L R N G H K G L R I I C S 320 gaagatgagcagagccgcacctget ggetggetgecttcogcetcttcaagtacggggtg 1020

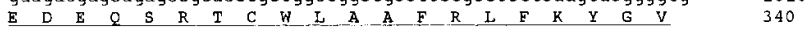
cagctgtacaagaattaccagcaggcacagtctegceatctgcatccatcttgtttgggc $\quad 1080$ $\begin{array}{lllllllllllllllllllll}Q & L & Y & K & N & Y & Q & Q & A & Q & S & R & H & I & H & P & S & C & \text { L } & G & 360\end{array}$ tccccacccttgagaagtgcctcagataataccctggtggecatggacttctctggecat 1140

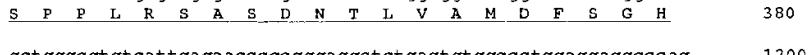
getgggcgtgtcattgagaaccecegggaggctetgagtgtggecetggaggaggeccag 1200 gectggaggaagaagacaaaccaccgectcagcetgcecatgceagcetccggcacgagc 1260

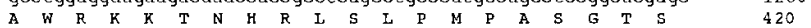
ctcagtgeagcetgttectggtcegggagagtcageggaaceccagggetttgtectet 1320 $\begin{array}{lllllllllllllllllllll}L & S & A & A & C & S & W & S & G & R & V & S & G & T & P & R & A & L & S & S\end{array}$ 135.1 447

Figure 1. Coding region and predicted amino acid sequences of Grb7 and Grb7V isoforms isolated from human esophageal carcinoma tissue (EC3). The underlined amino acid sequence indicates the GM region and SH2 domain. The bold sequences indicate the proline-rich sequences in the $\mathrm{NH}_{2}$-terminal region of Grb7 proteins. The arrows represent potential splicing sites. These Grb7 and Grb7V sequences are available from GenBank/EMBL/DDBJ under accession numbers AB008789 and AB008790, respectively.

terminus (Fig. 3 B, Grb7-C). Murine Grb7 has been reported to be tyrosyl phosphorylated after EGF stimulation in breast carcinoma cell lines (13). The tyrosyl phosphorylation profile of Grb7 and Grb7V proteins was then analyzed using the KYSE410 esophageal carcinoma cell line with or without EGF additions as shown in Fig. 3 B. We found that the 59-kD Grb7 protein became tyrosyl phosphorylated in EGF-stimulated as compared to quiescent serum-starved cells. In contrast, EGF additions were unable to increase the tyrosyl phosphorylation of the $50-\mathrm{kD}$ Grb7V protein.
Analysis of Grb7 expression in human esophageal carcinomas. We have previously reported overexpression of the Grb7/Grb7V gene in invasive esophageal carcinoma tissues (9). In this study, expression of Grb7/Grb7V proteins in invasive esophageal carcinomas was determined by immunohistochemistry using an $\mathrm{NH}_{2}$-terminal Grb7 specific antibody $(\mathrm{N}$ 20; Santa Cruz Biochemistry). As demonstrated in Fig. $4 A$, the invading esophageal carcinoma cells overexpress the proteins, whereas other cells and surrounding tissue elements have little if any expression. To examine the potential clinical 
Grb7

Mig-10

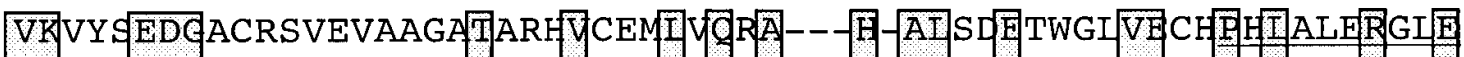

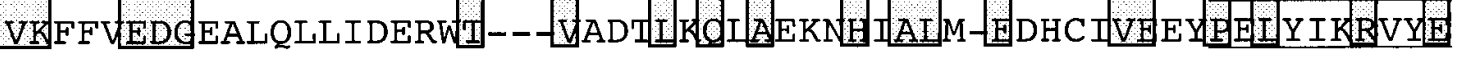

Grb7

Mig-10

DHRSVVEVQAA

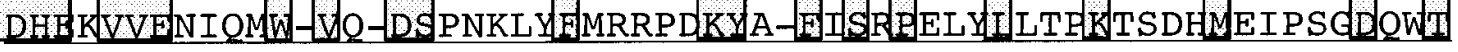

Grb7

Mig-10

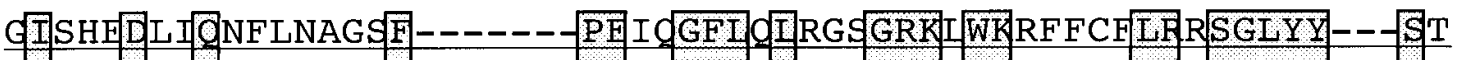

Grb7

Mig-10

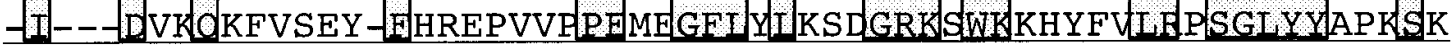

Grb7

Mig-10

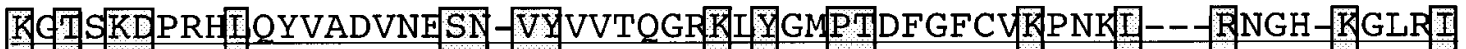

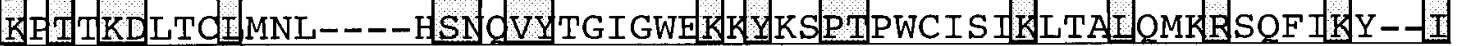

Grb7

Mig-10

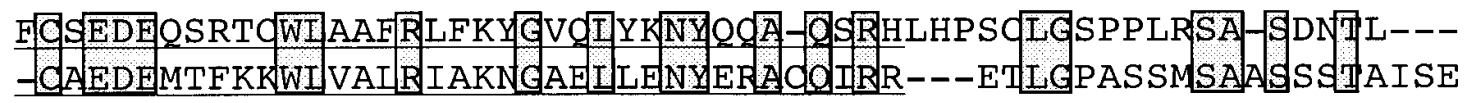

B

Grb7

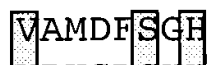

VP HSI SHE

Grb7V

Figure 2. This is a sequence comparison of the GM domains of Grb7 and Mig-10 proteins. $(A)$ Regions of identity are shaded. The underlined amino acid sequences indicate the PH domains. $(B)$ Scheme demonstrating the structural and functional domains of human Grb7 isoforms and C. elegans Mig-10. The Mig-10 gene encodes two isoforms (Mig-10a and 10b) as described (6). Black boxes indicate proline-rich sequences that bind to the SH3 domain of c-Abl.

significance of Grb7 and Grb7V expression, a specific RTPCR was performed to distinguish the parent molecule from its isoform in human esophageal tumor tissues as well as in regional lymph nodes containing metastatic disease, as shown in Fig. 4, $B$ and $C$. The primers selected spanned the spliced region to detect Grb7 as a 505-bp band and Grb7V as 417-bp band, respectively. The Grb7 mRNA expression was detected in 20 of 43 tumors (47\%). In addition, expression of the Grb7V isoform was present in eight of Grb7-positive (40\%) but not in Grb7-negative tumors. More importantly, Grb7V expression was found only in the carcinomas that had invaded the adventitia and, therefore, demonstrated a metastatic phenotype. In this regard, we have previously shown that increased expression of Grb7 was associated with invasive esophageal carcinomas that also overexpress RTK, as exemplified by tumors EC4 and EC5 presented in Fig. 4, $B$ and $C$. In contrast, Grb7V expression was not only recognized in RTK-overexpressing carcinomas (EC4) but also in invasive carcinomas, without such overexpression as exemplified by EC2 and EC3. Additionally, we searched for Grb7 and Grb7V expression in regional lymph nodes derived from eight metastatic carcinomas of the esopha- gus. Five metastatic lymph nodes contained detectable Grb7 expression that matched the primary tumors. It is noteworthy that Grb7-positive lymph nodes containing mestastatic disease had enhanced expression of Grb7V compared to the original tumor tissues as demonstrated by the representative examples EC6 in Fig. 4, $B$ and $C$. These findings suggest a relationship of Grb7V expression to invasion and metastatic spread of human esophageal carcinoma tumor cells.

Effects of reduced Grb7 protein levels on the migration properties of human esophageal carcinoma cells. Finally, the effect of antisense mRNA expression on Grb7 protein levels with respect to alterations of the phenotype of KYSE410 esophageal carcinoma cells was investigated. Stable cloned cell lines were isolated and grown for further analysis after transfection of mock DNA or antisense Grb7-expression vectors containing the neomycin resistance gene (11). As shown by the immunoblots demonstrated in Fig. $5 A$, mock DNA-transfected cells express both the $59-$ and $50-\mathrm{kD}$ proteins to a similar degree as observed in the parental KYSE410 esophageal carcinoma cell line. We obtained three independent stable clones designated as A-1, A-2, and A-3, that express variable 


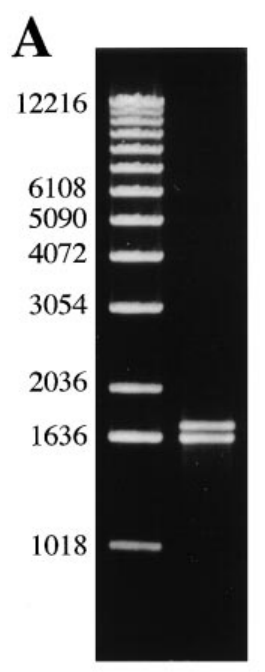

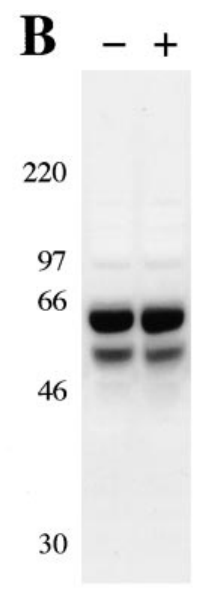

IB: Grb7-N

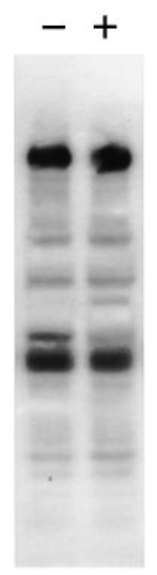

IP: Grb7-N IB: PY

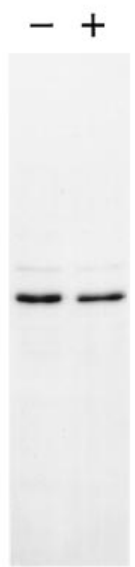

IB: Grb7-C
Figure 3. Transcription and protein expression of two Grb7 isoforms in a human esophageal cell line. $(A)$ A RT-PCR of the full coding regions of human Grb7 revealed two mRNA fragments (1731 bp and 1643 bp) in the KYSE410 cells. (B) Left lane shows immunoblot analysis using an antibody directed against the $\mathrm{NH}_{2}$-terminal of the human Grb7 protein. Two distinct proteins of 59 and $50 \mathrm{kD}$ are detected in KYSE410 cells with or without EGF stimulation. Middle lane shows tyrosyl phosphorylation of the proteins after immunoprecipitation with the anti- $\mathrm{NH}_{2}$-terminal Grb7 antibody. Phosphorylation of the 59-kD Grb7 protein was detected only in EGF-stimulated cells, whereas the 50-kD Grb7V isoform does not respond to EGF stimulation. The other bands have the predicted size of known proteins that bind to phosphorylated Grb7, such as RTK, SHPTP2, and Shc protein as previously described $(13,16)$. Right lane shows that the antibody directed against the $\mathrm{COOH}$ terminus of $\mathrm{Grb} 7$ reacts with the $59 \mathrm{kD}(\mathrm{Grb} 7)$ protein but not with the $50 \mathrm{kD}$ protein $(\mathrm{Grb} 7 \mathrm{~V})$, as it is truncated at the $\mathrm{COOH}$ terminus.

but low amounts of both Grb7 and Grb7V proteins after stable transfection of the antisense Grb7 expressing construct into KYSE410 cells. The expression of a control protein such as Grb2 was not effected in each cell line. There was no difference with respect to the doubling times of the transfectants; $30.5 \pm 1.8 \mathrm{~h}$ for A-1, $29.9 \pm 2.6 \mathrm{~h}$ for A-2, and $30.7 \pm 1.1 \mathrm{~h}$ for $\mathrm{A}-3$, compared to $31.2 \pm 1.1 \mathrm{~h}$ for parental KYSE410 cells and $29.5 \pm 1.6 \mathrm{~h}$ for mock DNA-transfected cells, indicating that the downregulation of Grb7 expression by antisense RNA had no growth inhibitory effects on these esophageal carcinoma cell lines. However, the potential for cell invasion was altered as demonstrated by the Matrigel assay (14). Fig. $5 B$ depicts the number of cells invading the Matrigel complex either as a basal rate or after stimulation with EGF. The results demonstrated that esophageal carcinoma cell invasion was strikingly suppressed when Grb7 and Grb7V protein levels were reduced by expression of the antisense RNA.

\section{Discussion}

Transmission of intracellular signals requires the sequential interaction of signaling molecules (15). Specific amino acid sequences present in certain proteins have been shown to be essential with respect to forming these molecular interactions. Proteins containing phosphotyrosine motifs are well known targets for binding of signaling molecules that have $\mathrm{SH} 2$ do-
A

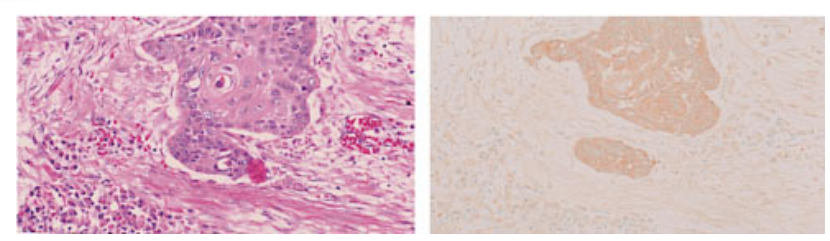

B Grb7 $\begin{array}{lllll}E C 1 & E C 2 & E C 3 & E C 4 & E C 5\end{array}$

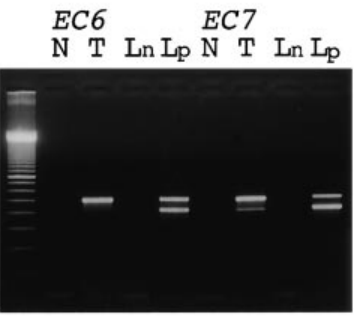

GAPDH $E C 1 \quad E C 2$ EC3 $E C 4$ EC5

EC6

EC7
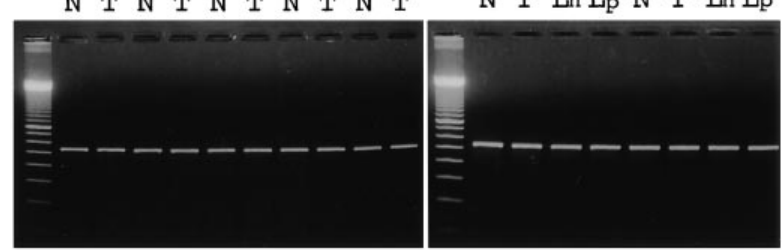

C

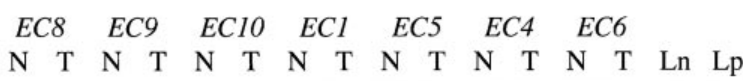

97

66

46

Figure 4. Protein and RNA expression of Grb7 in clinical tumor samples obtained at the time of surgical resection. $(A)$ Representative example of an invasive esophageal carcinoma (EC4). Left lane shows hematoxylin and eosin staining $(\times 100)$. Right lane shows immunohistochemical staining reaction using an antibody specific for the $\mathrm{NH}_{2}$ terminus of the Grb7 protein. Positive staining for Grb7 protein expression is present in invasive nests of esophageal carcinoma cells ( $\times 100)$. (B) Expression of Grb7 isoforms and GAPDH in human esophageal tissues and lymph nodes as measured by RT-PCR. Esophageal carcinoma tumors $(T)$, normal adjacent mucosa $(N)$, regional lymph nodes without metastasis $(L n)$, and lymph nodes with metastasis $(L p)$ were studied. The case numbers are represented in italics. All of the tumors presented are derived from invasive or metastatic esophageal carcinomas, except for EC1. Molecular markers: $100 \mathrm{bp}$ ladder. $(C)$ Immunoblot analysis using an antibody for the $\mathrm{NH}_{2}$ terminus of $\mathrm{Grb} 7$ protein demonstrates different expression of 59-kD Grb7 and 50-kD Grb7V proteins in tumors, and are similar to the results obtained by RT-PCR analysis.

mains, such as Grb, Shc, insulin receptor substrate-1, and recently reported c-Met binding domain of the Gab1 protein. For example, the murine Grb7 cDNA was originally isolated and characterized using the CORT (cloning of receptor targets) method by taking advantage of the interaction between the $\mathrm{SH} 2$ domain and the autophosphorylated kinase region of 
A

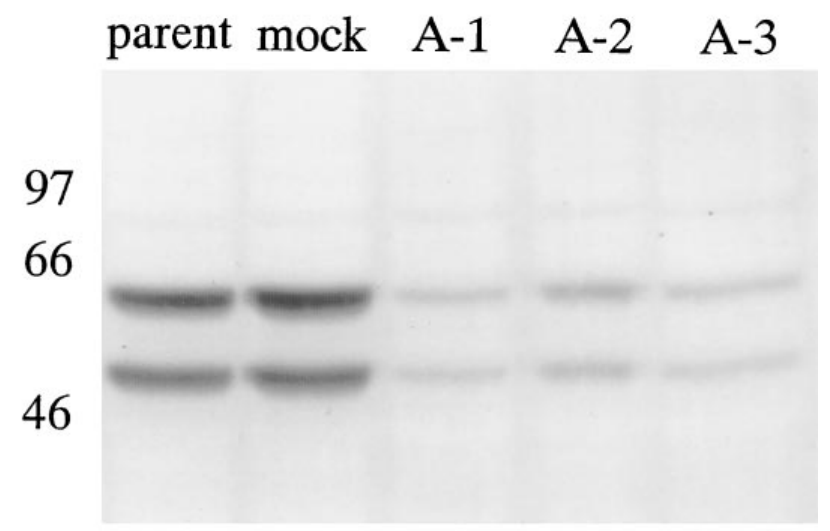

IB: anti-Grb7(N)

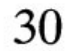

21

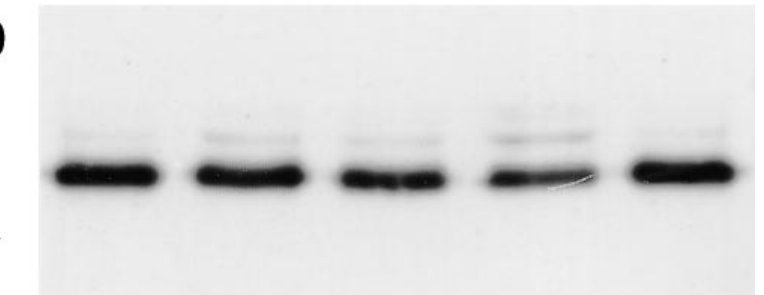

IB: anti-Grb2

B

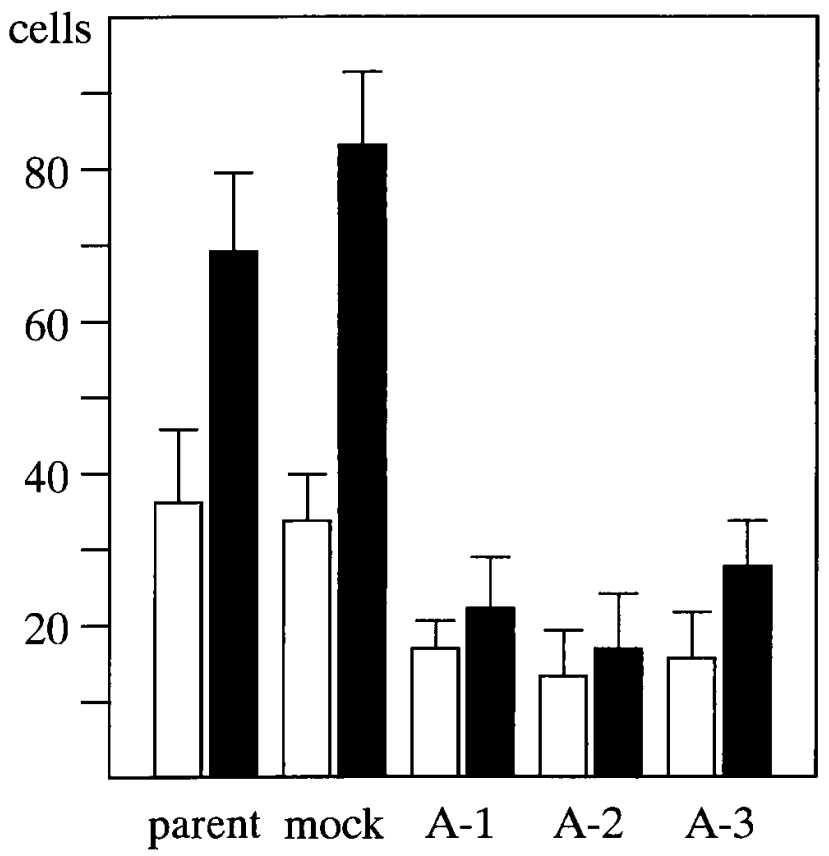

Figure 5. Effect of antisense Grb7 RNA expression on the phenotype of esophageal carcinoma cells. (A) Analysis of Grb7 expression in KYSE410 esophageal carcinoma cell clones transfected with antisense Grb7 ( $A-1, A-2$, and $A-3)$ compared to parental (parent) and mock DNA-transfected KYSE410 cells. Expression of a Grb2 control protein was not altered in these cell lines. $(B)$ Results of the Matrigel invasion assay. The number of cells invading into the Matri- the EGF receptor (6). In the present study, a Grb7 protein containing a $\mathrm{SH} 2$ domain in the $\mathrm{COOH}$ terminus was shown to be tyrosyl phosphorylated by EGF stimulation in esophageal carcinoma cells. Thus, the activated EGF receptor will bind the Grb7 SH2 domain and phosphorylate the protein. On the other hand, tyrosyl-phosphorylated Grb7 was not detectable in cell serum-starved quiescent cells. The mechanism of Grb7 dephosphorylation has not been identified. One possibility is that protein tyrosine phosphatases (PTP) may be involved in the dephosphorylation of Grb7. Recently, a member of this PTP family named SHPTP2 or PTP1D was found to be associated with the SH2 domain of Grb7 (16). Therefore, wild-type Grb7 is presumably dephosphorylated by the PTP activity after a Grb7 interaction with SHPTP2 via its $\mathrm{SH} 2$ domain. In contrast, dephosphorylation of Grb7V that clearly lacks this $\mathrm{SH} 2$ domain in the $\mathrm{COOH}$ terminus may not be possible even in serum-starved quiescent cells. Because Grb7V cannot be targeted by such PTP binding, the tyrosyl phosphorylation of the protein found in esophageal carcinoma cells is of interest with respect to metastatic potential in the context of a constitutive activated signal transduction pathway.

The Grb7V is composed of a proline-rich sequence and a GM domain. The proline-rich sequence is generally thought to interact with SH3 WW domains $(15,17)$. Recent studies of human Grb10, a member of the Grb7 family (18), revealed that the $\mathrm{NH}_{2}$-terminal proline-rich region SLPAIPNPFPEL may bind to the SH3 domain of the c-Abl oncoprotein. The c-Abl protein also contains a tyrosine kinase domain. More recently, the $\mathrm{SH} 3$ domain of c-Abl was found to bind to a similar proline-rich sequence of the ataxia telangiectasia mutated protein (19) and c-Abl will tyrosyl phosphorylate the ataxia telangiectasia mutated protein directly (20). A similar proline-rich SLPSIPNPFPEL sequence is also present at aa 63-74 of the Grb7 and Grb7V proteins. In this regard, preliminary in vitro binding data demonstrates a direct interaction of the Grb7V isoform to the c-Abl SH3 domain (our unpublished observation). Although a SH3-containing tyrosine kinase such as c-Abl protein might phosphorylate both Grb7 and Grb7V proteins, the Grb7V isoform lacking the $\mathrm{SH} 2$ domain may not be sensitive to PTP activity and this could contribute to phosphorylation of the molecule in esophageal carcinoma cells.

We have previously reported that tyrosyl phosphorylation of the insulin receptor substrate- 1 is followed by binding to $\mathrm{SH} 2$-containing proteins, such as Grb2, and this interaction induces the mitogen-activated protein kinase signaling pathways associated with transformation of cells to the malignant phenotype (10). Because many tyrosine residues are present in the GM region of both Grb7 and Grb7V as shown in Fig. 2, this domain may be essential for Grb7 function. It is of interest that the GM region includes a PH domain. Recent studies suggest that the PH domain interacts with $\mathrm{G} \alpha \beta$ subunits (21) and phospholipids (22) and may be involved in signal transduction pathways related to cell growth. Our previous investigations also indicate that the $\mathrm{PH}$ domain was required for effective interaction of signaling molecules related to malignant transforma-

gel matrix were determined for each clone. White bars indicate the basal invasion rate and black bars indicate the rate of invasion after stimulation of chemotaxis by EGF. Results are derived from three individual experiments and error bars indicate the standard deviation from the mean. 
tion of hepatocytes (11). However, the role of the GM domain in Grb7 and its isoforms has not been clarified. A possible clue to its function is derived from the genetic analysis of $C$. elegans Mig-10 mutant phenotypes. An amber Mig-10 (ct41) mutant results in a protein with a truncation upstream to the GM region. Such a mutation induces an incomplete long range anterioposterior migration of neurons. Thus, the function of Mig10 is closely associated with directional cell migration (4). This finding is consistent with our observations that Grb7 and Grb7V expression is related to metastatic spread of esophageal carcinoma. Indeed, in vitro analysis using antisense constructs revealed that lowering the intracellular levels of Grb7 and Grb7V proteins was associated with reduced invasion of esophageal carcinoma cells into Matrigel.

Human esophageal carcinomas are known to be highly invasive, frequently metastasize, and, therefore, have a poor prognosis (23). The present investigation has revealed a relationship between expression of Grb7 and the novel Grb7V isoform and the biologic properties of invasion and metastatic spread of these cells. Further studies will be needed to identify signal transduction pathways and molecules that interact with the GM domain of Grb7 (20) to further clarify its molecular role in this disease.

\section{Acknowledgments}

We thank Akira Nakagawara (Chiba Cancer Center, Chiba, Japan) for discussion, David Baltimore (Massachusetts Institute of Technology, Cambridge, MA) for providing c-Abl cDNA, and Tomoyuki Shishido (The Rockefeller University, New York City, NY) for helpful information. We also thank K. Ogata, J. Miyake and T. Shimooka for technical assistance.

This work was supported by Research Fund for Digestive Molecular Biology, Haraguchi Memorial Cancer Research Fund, Research Fund for Japan Medical Association, Japan Society for the Promotion of Science (Fujita Memorial), Inamori Foundation, a Grant-in-Aid from Ministry of Education, Science, Sports, and Culture of Japan and CA35711 from the National Institutes of Health, Bethesda, MD.

\section{References}

1. Poste, G., and I.J. Fidler. 1980. The pathogenesis of cancer metastasis. Nature. 283:139-146.

2. Liotta, L.A., P.S. Steeg, and W.G. Stetler-Stevenson. 1991. Cancer metastasis and angiogenesis: an imbalance of positive and negative regulation. Cell. 64:327-336.

3. Wood, W.B., editor. 1988. The neomatode Caenorhabditis elegans. Cold Spring Harbor Laboratory Press, Cold Spring Harbor, NY.

4. Manser, J., and W.B. Wood. 1990. Mutations affecting embryonic cell mi- grations in Caenorhabditis elegans. Dev. Gen. 11:49-64.

5. Manser, J., C. Roonprapunt, and B. Margolis. 1997. C. elegans cell migration gene mig- 10 shares similarities with a family of $\mathrm{SH} 2$ domain proteins and acts cell nonautonomously in excretory canal development. Dev. Biol. 184: $150-164$.

6. Margolis, B., O. Silvennoinen, F. Comoglio, C. Roonprapunt, E.Y. Skolnik, A. Ullrich, and J. Schlessinger. 1992. High-efficiency expression/cloning of epidermal growth factor-receptor-binding proteins with Src homolguey 2 domains. Proc. Natl. Acad. Sci. USA. 89:8894-8898.

7. Ooi, J., V. Yajnik, D. Immanuel, M. Gordon, J.J. Moskow, A.M. Buchberg, and B. Margolis. 1995. The cloning of Grb10 reveals a new family of SH2 domain proteins. Oncogene. 10:1621-1630.

8. Daly, R.J., G.M. Sanderson, P.W. Janes, and R.L. Sutherland. 1996. Cloning and characterization of GRB14, a novel member of the GRB7 gene family. J. Biol. Chem. 271:12502-12510.

9. Tanaka, S., M. Mori, T. Akiyoshi, Y. Tanaka, K. Mafune, J.R. Wands, and K. Sugimachi. 1997. Coexpression of Grb7 with epidermal growth factor receptor or Her2/erbB2 in human advanced esophageal carcinoma. Cancer Res. 57:28-31.

10. Tanaka, S., T. Ito, and J.R. Wands. 1996. Neoplastic transformation induced by insulin receptor substrate-1 overexpression requires an interaction with both Grb2 and Syp signaling molecules. J. Biol. Chem. 271:14610-14616.

11. Tanaka, S., and J.R. Wands. 1996. A carboxy-terminal truncated IRS-1 dominant negative protein reverses the human hepatocellular carcinoma malignant phenotype. J. Clin. Invest. 98:2100-2108.

12. Peverali, F.A., M. D'Esposito, D. Acampora, G. Bunone, M. Negri, A. Faiella, A. Stornaiuolo, M. Pannese, E. Migliaccio, A. Simeone, et al. 1990. Expression of HOX homeogenes in human neuroblastoma cell culture lines. Differentiation. 45:61-69.

13. Stein, D., J. Wu, S.A.W. Fuqua, C. Roonprapunt, V. Yajnik, J.J. Moskow, A.M. Buchberg, C.K. Osborne, and B. Margolis. The SH2 domain protein GRB-7 is co-amplified, overexpressed and in a tight complex with HER2 in breast cancer. EMBO (Eur. Mol. Biol. Organ.) J. 13:1331-1340.

14. Albini, A., Y. Iwamoto, H.K. Kleiman, G.R. Martin, S.A. Aaronson, J.M. Kozlowski, and R.N. McEwan. 1987. A rapid in vitro assay for quantitating the invasive potential of tumor cells. Cancer Res. 47:3239-3245.

15. Pawson, T. 1995. Protein modules and signaling networks. Nature. 373: 573-580.

16. Keegan, K., and J.A. Cooper. 1996. Use of the two hybrid system to detect the association of the protein-tyrosine-phosphatase, SHPTP2, with another SH2-containing protein, Grb7. Oncogene. 12:1537-1544.

17. Bork, P., and M. Sudal. 1994. The WW domain: a signaling site in dystrophin? Trends. Biochem. Sci. 19:531-533.

18. Frantz, J.D., S. Giorgetti-Peraldi, E.A. Ottinger, and S.E. Shoelson. 1997. Human GRB-IRß/GRB-10. J. Biol. Chem. 272:2659-2667.

19. Shafman, T., K.K. Khanna, P. Kedar, K. Spring, S. Kozlov, T. Yen, et al. 1997. Interaction between ATM protein and c-Abl in response to DNA damage. Nature. 387:520-523.

20. Baskaran, R., L.D. Wood, L.L. Whitaker, C.E. Canman, S.E. Morgan, Y. Xu, C. Barlow, D. Baltimore, A. Wynshaw-Boris, M.B. Kastan, and J.Y. Wang. 1997. Ataxia telanfiectasia mutant protein activates c-Abl tyrosine kinase in response to ionizing radiation. Nature. 387:516-519.

21. Touhara, K., J. Inglese, J.A. Pitcher, G. Show, and R.J. Lefkowitz. 1994. Binding of $\mathrm{G}$ protein $\beta \gamma$-subunits to pleckstin homolguey domains. J. Biol. Chem. 269:10217-10220.

22. Harlen, J.E., P.J. Hajduk, H.S. Yoon, and S.W. Feski. 1994. Pleckstin homolguey domains bind to phosphatidylinositol-4, 5-bisphophate. Nature. 371: 168-170.

23. Sugimachi, K., M. Watanabe, N. Sadanaga, M. Ikebe, K. Kitamura, M. Mori, and H. Kuwano. 1994. Recent advances in the diagnosis and surgical treatment of patients with carcinoma of the esophagus. J. Am. Coll. Surg. 178 363-368. 